\title{
Cement Take Evaluation and Prediction based on Empirical Relationships and Support Vector Regression
}

\author{
FAN Guichao ${ }^{1, a}$, ZHONG Denghua ${ }^{1, b}$, WANG Jiajun ${ }^{1, c}$ and REN Bingyu, ${ }^{1, d}$ \\ ${ }^{1}$ State Key Laboratory of Hydraulic Engineering Simulation and Safety, Tianjin University, Tianjin \\ 300072, China \\ âfgc@tju.edu.cn, bdzhong@tju.edu.cn, cjiajun_2014_bs@tju.edu.cn, ${ }^{d}$ renby@tju.edu.cn
}

\begin{abstract}
Keywords: Cement take, Permeability, Transmissivity, Rock quality classification, Support vector regression (SVR)
\end{abstract}

Abstract: Cement grouting is a common method to improve the dam foundation, however, the cement take needed for improvement is difficult to evaluate because of the complexity of the rock foundation and the uncertainty of the influence factors. Although grouting design depends largely on the permeability of the dam foundation, due to the anisotropy of the hydraulic paths and various flow properties of water and grout, it is difficult to obtain a direct relationship between the Lugeon values and the cement takes. In this paper, the cement take is evaluated by considering rock quality classification, Lugeon value and transmissivity as the influencing parameters. Simple and multivariate regression analysis are used to research the correlation of the cement take and the parameters, results indicate general correlations but low or moderate correlative coefficients. Additionally, support vector regression method is utilized to predict the cement take, the correlative coefficients become higher than the previous results, but the goodness of fitting is not very high. It seems that more research need to understanding the influencing mechanism of the cement takes.

\section{Introduction}

Cement grouting is commonly used to reduce hydraulic conductivity and improve the strength of the dam foundation. Reasonable estimation of potential cement take is of fundamental importance [1]. However, since the dam foundation is under the surface of the ground, the crack system and crack apertures are relatively unknown. Therefore, the cement take is very difficult to predict.

Generally, a dam foundation with a higher permeability will need more cement take. Sadeghiyeh et al. compared the cement takes with the Lugeon values and find a general consistency; however they also observed somewhat opposing trends especially where more pressure used for grouting compared to the WPT [2]. Yang researched the relationship between cement take and the strata, zone of dam foundation, depth of grout section, injection pressure, and the Lugeon value using the back-propagation neural network method [3]. The results indicate that the accuracy levels estimated by this method is higher than the original estimated method which only considering the Legeon value. Sohrabi-Bidar et al. estimated the correlation between grout take and Q-value, Lugeon number, Secondary permeability index (SPI) value and joint apertures in the Bakhtiari dam site [4]. The results show that there is a general correlation between grout take and the above mentioned parameters; however the correlative coefficients of determination for the best fitted relations are low.

Theoretically, there are many factors that affect the cement take needed for improving dam foundations, including rock mass properties, grout mix properties, grouting procedure parameters and so on. Since some factors are difficult to obtain or quantify, and some factors may have combined effects, it is not possible to clearly define the role of each factor [3]. In the case of the grouting in rocks, the hydrogeological condition (including geological and permeability condition) of rock mass under the dam foundation is the most important property which affects the cement take. Therefore, in this paper, the rock quality classification, which is evaluated by rock mass properties including rock compressive strength (RCS), joint spacing (JS), acoustic velocity (AV), and rock quality designation (RQD), is proposed to be one of the factor that impact cement take. Additionally, the Lugeon value and transmissivity calculated from WPT are considered as other two factors. Then the relationship between 
the cement take and these parameters has been examined by using regression analysis methods. Ultimately, support vector regression method is utilized for cement take predicting.

\section{Methodology}

\section{Rock quality classification}

There are many methods in rock quality classification. Such as Barton rock quality classification (Q system), rock mass rating (RMR) classification, rock structure rating (RSR) system, BQ grading standards in engineering rock mass, and HC classification standards in geological investigation. In this paper, a modified RSR classification method which includes four evaluation indexes is adopted. These evaluation indexes are rock compressive strength (RCS), joint spacing (JS), acoustic velocity (AV), and rock quality designation (RQD), respectively. The rock mass quality can be classified into six grades by comprehensively evaluating. The rock quality classification criterion is listed in Table 1 .

Table 1 . The rock quality classification criterion

\begin{tabular}{cccccc}
\hline Grade & RCS $[\mathrm{MPa}]$ & JS $[\mathrm{cm}]$ & $\mathrm{AV}[\mathrm{m} / \mathrm{s}]$ & $\mathrm{RQD}[\%]$ & $\mathrm{RQR}^{*}$ \\
\hline I & $>100$ & $>100$ & $>5000$ & $>85$ & 1 \\
II & $80 \sim 100$ & $50 \sim 100$ & $4000 \sim 5000$ & $60 \sim 85$ & 2 \\
III $_{1}$ & $60 \sim 80$ & $30 \sim 50$ & $3500 \sim 4000$ & $45 \sim 60$ & 3 \\
III $_{2}$ & $40 \sim 60$ & $10 \sim 30$ & $3000 \sim 3500$ & $30 \sim 45$ & 4 \\
IV & $20 \sim 40$ & $<10$ & $2000 \sim 3000$ & $5 \sim 30$ & 5 \\
V & $<20$ & - & $<2000$ & $<5$ & 6 \\
\hline
\end{tabular}

Note: ${ }^{*} \mathrm{RQR}$ represents rock quality rating.

\section{Permeability from water pressure test}

The LU value is the best physical parameter for expressing the status of discontinuities in a dam foundation. Informations obtained from WPTs can be used to determine the water-cement ratio and grout injection pressure [5]. Furthermore, accoding to Houlsby, the LU value can also be used to determine whether the rock mass need to be grouted. WPT is the most common method applied for determination of rock mass permeability and mostly conducted using the Lugeon method. The LU value can be calculated by Eq. (1).

$$
L U=\frac{Q}{P \cdot L} .
$$

where $L U$ is the Lugeon value in $\mathrm{Lu} ; Q$ is the water take (i.e., discharge) in $\mathrm{L} / \mathrm{min} ; P$ is the effective pressure in $\mathrm{MPa}$; and $L$ is length of the tested interval in $\mathrm{m}$.

\section{Transmissivity of Fractured Rock}

The LU value is very useful to determine the permeability of the rock foundation, however, it just represents the average permeability of the test interval and tells little of the properties of the section of the borehole to grout and its ability to take grout and the predicted sealing caused by grouting [6]. Comparatively speaking, transmissivity is a better parameter, because the transmissivity of a borehole approximately followed a Pareto distribution which describes data sets which are dominated by a few very high values compared to many small value data. According to Moye [7], the transmissivity of a borehole section can be calculated by WPT as:

$$
T=\frac{Q_{w} \rho_{w} g}{2 \pi \cdot \Delta P_{w}}\left[1+\ln \left(\frac{L}{2 r_{b}}\right)\right] .
$$


where $\Delta P_{w}$ is the injection over-pressure, $Q_{w}$ is the water flow rate and $r_{b}$ is the radius of the borehole.

\section{Support vector regression (SVR)}

Generalized from Support vector machines, SVR is formulated as an optimization problem by first defining a convex $\varepsilon$-insensitive loss function to be minimized and finding the flattest tube that contains most of the training instances [8]. In the SVR method, there are three important parameters, i.e., penalty coefficient $C$, insensitive loss coefficient $\varepsilon$ and kernel parameter $\gamma$. Since the penalty coefficient $C$ represents the degree of penalty for the sample data outside the $\varepsilon$-tube, and it impacts the complaxity of the model. Additionally, the insensitive loss coefficient $\varepsilon$ determines the width of the tube, and it impacts the generalization capability of the model. Moreover, a Gaussian radial basis function, used as a kernel function, represents the correlative degree of support vectors, and impacts the generalization capability and robustness of the model. Therefore, The success of the SVR in estimating problem is dependent on the accurate selection of these parameters. For this purpose, the grid search method is used to select the optimal parameters.

\section{Case study}

\section{General}

Hydropower project $\mathrm{X}$ in China is taken as a case study. There are numerous dam monoliths in this project, which are considered as grouting units for simplicity. In this paper, 289 boreholes of 13 grouting units in the spillway dam monolith is selected as the study region for case study.

Investigation and analysis of the rock quality, $L U$ value and cement take of the study region

According to the classification method proposed in this paper, the rock quality of the study region can be classified into three sorts, 66, 12 and $22 \%$ of the rock are sorted into grade III 1, III 2 and IV, respectively. It is obvious that the dominating rock quality grade is III 1. According to the rock quality classification criterion, the rock mass of the study region is slightly or moderate permeable.

To determine the permeability of the dam foundation in the study region, 289 boreholes were drilled and 2800 WPTs were carried out, the results are plotted in Fig. 1 (left). As shown in the figure, for all rock in the study region, the highest frequency of LU value interval is between 3 and 10. The majority of the boreholes for grade III 1, III 2 and IV are all indicate the LU value between 3 and 10. That means the study region is slightly or moderate permeable.
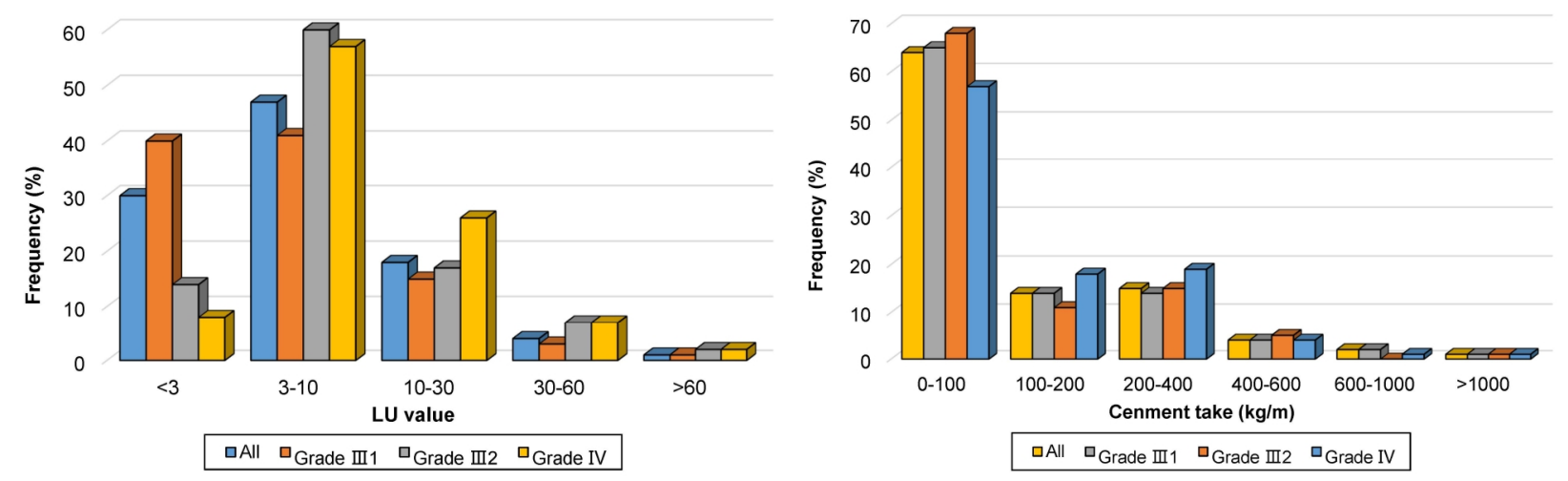

Fig. 1. The distribution of LU values (left) and cement takes (right)

The cement take of each grouting interval was automatically measured and collected during grouting. Therefore, the statistical results of cement take can be easily obtained, as shown in Fig. 1 (right). It is obvious that the dominating proportion of cement take is less than $100 \mathrm{~kg} / \mathrm{m}$. The result is in accordance with the LU value distribution. 


\section{Results and discussion}

\section{Relationship between cement take and rock quality, $\mathrm{LU}$ value and transmissivity}

The correlation between cement take and LU value and transmissivity are plotted in Fig. 2 by using simple linear regression method. To obtain a good data observability, Fig. 2 is plotted in logarithmic coordinates. The regression equations are easily obtained, as shown in Eqs. (10) and (11).

$$
\begin{gathered}
C T=2.34 L U+99.29, \quad R^{2}=0.2168 \\
C T=1.05 \times 10^{7} \times T+69.83, \quad R^{2}=0.4053
\end{gathered}
$$
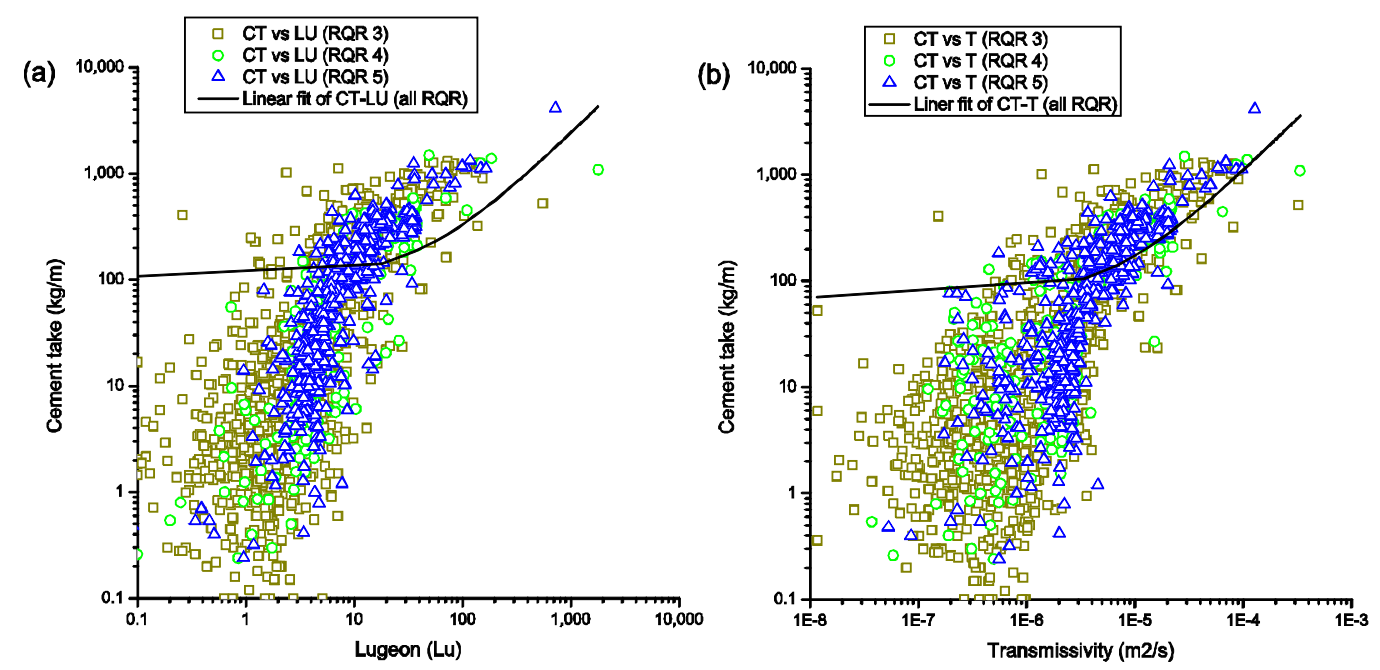

Fig. 2. The correlation between cement take and LU value (a) and transmissivity (b).

It is concluded from Eqs. (10), (11) and Fig. 2 that there is a positive relationship between cement take and LU value and transmissivity, where the cement take increases with increasing the LU value or transmissivity. As can be seen the cement take has a stronger correlation with transmissivity than LU value. However, the correlation coefficients $\mathrm{R}^{2}$ of these regressions are still very low, which indicates a poor overall goodness-of-fit.

For further study, multivariate linear regressions were performed to determine the effects that rock quality classification, permeability and transmissivity had on the cement take. After multivariate linear regressions analyses, the regression function is obtained as follow.

$$
C T=-1.36 L U+1.43 \times 10^{7} \times T-1.02 R Q R+67.81
$$

The correlation coefficient $\mathrm{R}^{2}$ of this regression is 0.4258 , which shows a poor correlation since the plotted data are very high scattered. However, it is better than the simple linear regression.

\section{Estimation and prediction of the cement take with support vector regression}

In order to ensure the generalization ability of the algorithm, the data points in the dataset are divided averagely into two part, one half is utilized to constructing the model and training, the other half is used for assessment of degree of accuracy and robustness. 


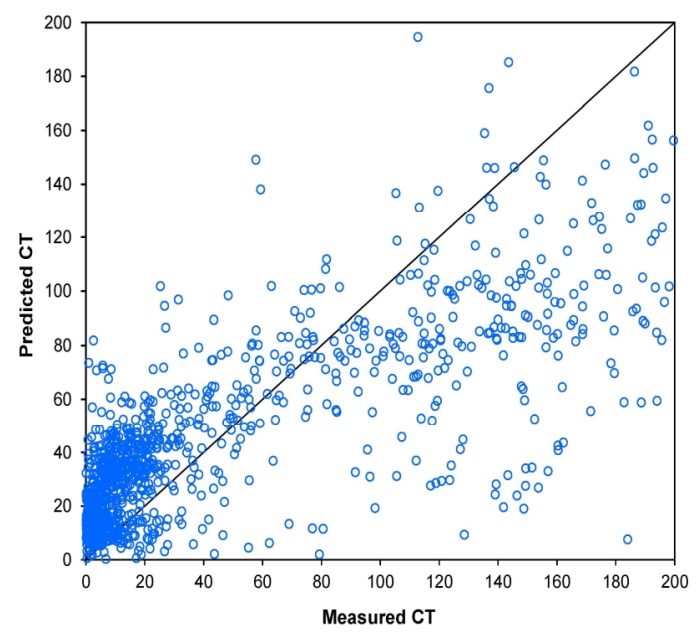

Fig. 3. Comparison between measured and predicted cement take.

By using grid search method, the adjusted parameters with maximal accuracy are selected as the most appropriate parameters. Consequently, the performance indices, mean-squared error (MSE), squared correlation coefficient $\left(\mathrm{R}^{2}\right)$, mean absolute difference (MAD) and relative mean absolute difference (RMAD) were obtained as $0.0007,0.6604,0.0145$ and 0.4708 , respectively. The correlation between measured and predicted cement take is shown in Fig. 3. As can be seen that the correlation coefficient is higher than the previous methods. However, the accuracy of prediction is not very high since the plotted data are very high scattered and there is a generally poor corelation. It is a good explanation that there are other unknown influencing parameters exist rather than only the rock mass properties and the interaction among all the parameters together influences the results.

\section{Conclusion}

In this paper, the cement take is examined against the rock properties parameters, such as rock quality, LU value and transmissivity. The relationships between cement take and these parameters are studied by simple linear regression and multivariate regression methods. The results show general correlations between cement take and the parameters but low correlative coefficients duo to the scattered data points. SVR is utilized to evaluate and predict cement take. The correlative coefficients are higher than the previous methods, but the result shows a poor goodness of fitting. It seems that there are other unknown influencing parameters exist rather than only the hydrogeological rock mass properties and the interaction among all the parameters together influences the results. Consquently, it needs more insightful research to obtain a reliable predictive relation for the cement take.

\section{Acknowledgements}

This work was financially supported by the National Natural Science Foundation of China (51409186, 51409188 and 51339003).

\section{References}

[1] Elledge, B. S., Dubeau, M., \& Heenan, D. M. Modeling Grout Injection Volume in Fractured Rock Using Borehole Imagery. Grouting and Deep Mixing (2012), p.1055-1064.

[2] Sadeghiyeh, S. M., Hashemi, M., \& Ajalloeian, R. Comparison of permeability and groutability of Ostur dam site rock mass for grout curtain design. Rock Mech Rock Eng, (2013), 46(2), 341-357.

[3] Yang, C. P. Estimating cement take and grout efficiency on foundation improvement for li-yu-tan dam. Eng Geol, (2004), 75(1), 1-14. 
[4] Sohrabi-Bidar, A., Rastegar-Nia, A., \& Zolfaghari, A. Estimation of the grout take using empirical relationships (case study: Bakhtiari dam site). Bull Eng Geol Environ, (2016), 75(2), 425-438.

[5] Azimian, A., \& Ajalloeian, R. Permeability and groutability appraisal of the nargesi dam site in iran based on the secondary permeability index, joint hydraulic aperture and lugeon tests. Bull Eng Geol Environ, (2015), 74(3), 845-859.

[6] Stille, H., Gustafson, G., \& Hassler, L. Application of new theories and technology for grouting of dams and foundations on rock. Geotech Geol Eng, (2012), 30(30), 603-624.

[7] Moye, D. G. Diamond drilling for foundation exploration. Civ Eng Trans Inst Eng Aust, (1967), 45(17), 95-100

[8] Awad, M., \& Khanna, R. Support Vector Regression. Efficient Learning Machines. Apress. Chapter 4, (2015), p. 67-80 